Available online on 15.01.2019 at http://jddtonline.info
(C) 2011-18, publisher and licensee JDDT, This is an Open Access article which permits unrestricted
non-commercial use, provided the original work is properly cited

Open $\sigma_{\text {Access }}$

Research Article

\title{
Phytochemical screening and GC-MS analysis of bioactive compounds present in ethanolic leaves extract of Silybum marianum (L).
}

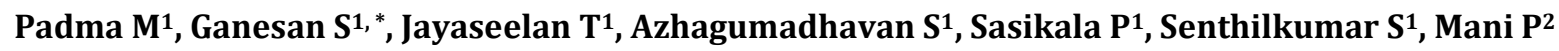 \\ 1P.G. and Research Department of Zoology and Biotechnology, A.V.V.M. Sri Pushpam College (Autonomous), Poondi - 613 503, Thanjavur District,
} Tamil Nadu, India.

2Dept. of Biotechnology, Annai College of Arts and Science, Kumbakonam, Tamilnadu, India.

\begin{abstract}
Objective: To investigate the phytochemicals and GC-MS analysis of ethanol extracts of Silybum marianum.

Methods: The air-dried leaves were powdered and subjected to selective sequential extraction using solvents of increasing polarity through percolation, ethanol to obtain an ethanolic extract. Then, each of the extracts was further subjected to gas chromatography-mass spectrometry. Results: Qualitative determination of the different biologically active compounds from crude extracts of Silybum marianum using gas chromatography-mass spectrometry revealed different types of high and low molecular weight chemical entities with varying amounts present in each of the extracts. These chemical compounds are considered biologically and pharmacologically important.

Conclusions: The study established the chemical composition and anticancer activity of the plant.
\end{abstract}

Keywords: Silybum marianum, Phytochemicals screening, GC-MS analysis, Bioactive compounds.

Article Info: Received 19 Nov 2018; Review Completed 30 Dec 2018; $\quad$ Accepted 02 Jan 2019; $\quad$ Available online 15 Jan 2019

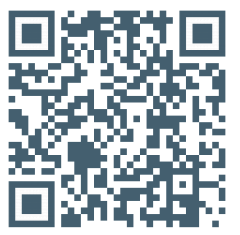

Cite this article as:

Padma M, Ganesan S, Jayaseelan T, Azhagumadhavan S, Sasikala P, Senthilkumar S, Mani P, Phytochemical screening and GC-MS analysis of bioactive compounds present in ethanolic leaves extract of Silybum marianum (L)., Journal of Drug Delivery and Therapeutics. 2019; 9(1):85-89 DOI: http://dx.doi.org/10.22270/jddt.v9i1.2174

Dr. Ganesan Sivamani, Assistant Professor, PG \& Research Department of Zoology and (Autonomous), Poondi, Thanjavur - 613503, Tamil Nadu, India.

\section{INTRODUCTION}

Plants play a significant role in the prevention and treatment of diseases and can even prevent and reduce the adverse effects of conventional treatments ${ }^{1}$. They can be a source of chemical compounds of biological and pharmacological importance. History reveals that plants are sources of successful drugs and will continuously be important for screening of new lead compounds 2 . The World Health Organization (WHO) estimated that $80 \%$ of the population of developing countries still relies on traditional medicines, mostly plant drugs, for their primary health care needs ${ }^{3}$. The various parts of the plant are used in the Indian traditional medicine for the treatment of various diseases like asthma, joint pain, lumbar pain and sprains, cough, eczema, malaria, rheumatism, swellings, venereal diseases $4,5,6$.

Plants are a rich source of secondary metabolites with interesting biological activities. In general, these secondary metabolites are an important source with a variety of structural arrangements and properties 7. Distinguished examples of these compounds include flavonoids, phenols and phenolic glycosides, saponins and cyanogenic glycosides
8. These compounds were synthesized by primary or rather secondary metabolism of living organisms. Secondary metabolites are taxonomically and chemically extremely diverse compounds with obscure function. They are widely used in human therapy, veterinary, agriculture, scientific research and countless other areas ${ }^{9}$. In this biochemicals are often referred to as Secondary metabolites which are useful to the traditional medicine system and these biochemicals are identified by using GC-MS technique 10 .

Gas Chromatography-Mass Spectroscopy, a hyphenated system which is a very compatible technique and the most commonly used technique for the quantification and identification purpose. The unknown organic compounds in a complex mixture can be determined by interpretation and also by matching the spectra with reference spectra ${ }^{11}$. In the last few years, gas chromatography-mass spectrometry (GCMS) has become firmly established as a key technological platform for secondary metabolites profiling in both plant and non-plant species 12,13, 14 .

Silybum marianum (L) is an essential medicinal plant that has volatile oils and other secondary metabolites. This 
common name is Milk thistle. The most common compound in milk thistle is silymarin, which is an isomeric mixture of flavonolignans (silybin, silychristin, and silydanin) present in $S$. marianum (L). Silymarin acts as a strong anti-hepatotoxic, which has been used for chronic inflammatory liver disease and liver cirrhosis 15. Milk thistle is hepatoprotectants for Cancer Patients. Toleration of cancer therapy may progress from using this herb, the reason is that it is blood and liver toxin clearing agents 16 . It has strong anticancer effects against breast, tumours, ectocervical and prostate 17. Nowadays, the use of medicinal plants and their bioactive phytocompounds and our scientific information about them comprises the modern field of the photoscience. This is a science created from the incorporation of a range of disciplines that have never been connected before, combining some various areas of economic, social, and political fields, chemistry, biochemistry, physiology, microbiology, medicine, and agriculture. Hence the present study focused on Phytochemical Screening and analysis of Bioactive Compounds of ethanolic leaves Extract of $S$. marianum (L.) using Gas chromatography and mass spectrometry.

\section{MATERIALS AND METHODS}

\section{Plant collection and Preparation of plant extracts}

Fresh, healthy, and young leaves of Silybum marianum were collected from the Himalayan Region, India. The leaves were cleaned and dried in shade for 7 days and then ground well to a fine powder. About $500 \mathrm{~g}$ of dry powder was extracted with ethanol $(80 \%)$ at $70^{\circ} \mathrm{C}$ by continuous hot percolation using Soxhlet apparatus. The extraction was continued for 24 hrs, and the ethanolic extract was then filtered and kept in a hot air oven at $40^{\circ} \mathrm{C}$ for $24 \mathrm{hrs}$ to evaporate the ethanol from it. A dark brown residue was obtained. The residue was kept separately in airtight containers and stored in a deep freezer.

\section{Phytochemical analysis tests}

Phytochemical analysis of an ethanolic extract of Silybum marianum leaves for secondary metabolites such as alkaloids, flavonoids, carbohydrates, proteins, phenols, saponins, tannins, terpenoids, phytosterols, and phlobatannins was done using standard methods 18 .

\section{Gas Chromatography-Mass spectrometry (GC-MS) analysis}

The GC-MS analysis was carried out using a Clarus 500 Perkin- Elmer (Auto System XL) Gas Chromatograph equipped and coupled to a mass detector Turbo mass gold Perking Elmer Turbomas 5.2 spectrometer with an Elite-1 (100\% Dimethyl ply siloxane), $300 \mathrm{~m} \times 0.25 \mathrm{~mm} \times 1 \mu \mathrm{m} \mathrm{df}$ capillary column. The instrument was set to an initial temperature of $110^{\circ} \mathrm{C}$ and maintained at this temperature for $2 \mathrm{~min}$. At the end of this period, the oven temperature was raised up to $280^{\circ} \mathrm{C}$, at the rate of an increase of $5^{\circ} \mathrm{C} / \mathrm{min}$, and maintained for $9 \mathrm{~min}$. Injection port temperature was ensured as $250^{\circ} \mathrm{C}$ and Helium flow rate as $1 \mathrm{ml} / \mathrm{min}$. The ionization voltage was $70 \mathrm{eV}$. The samples were injected in split mode as 10:1. Mass Spectral scan range was set at 45450 (MHz). The chemical constituents were identified by GCMS. The fragmentation patterns of mass spectra were compared with those stored in the spectrometer database using National Institute of Standards and Technology Mass Spectral database (NIST-MS). The percentage of each component was calculated from the relative peak area of each component in the chromatogram.

\section{Identification of Compounds}

Interpretation of mass spectrum of GC-MS was conducted using the database of National Institute Standard and Technology (NIST) having more than 62,000 patterns. The spectrum of the known component was compared with the spectrum of the known components stored in the NIST library. The name, molecular weight and structure of the components of the test materials were ascertained.

\section{RESULTS AND DISCUSSION}

\section{Phytochemical analysis}

Table 1: Phytochemical Analysis of S.m (L)

\begin{tabular}{|c|c|c|}
\hline S.No & Test & Result \\
\hline 1 & Alkaloids & + \\
\hline 2 & Flavonoids & + \\
\hline 3 & Saponins & - \\
\hline 4 & Tannins & + \\
\hline 5 & Terpenoids & - \\
\hline 6 & Phenol & + \\
\hline 7 & Cardiac glycosides & + \\
\hline 8 & Anthroquinones & + \\
\hline
\end{tabular}

The results of phytochemical characterization ethanolic extracts of $S$. marianum are shown in Table 1. Phytochemical analysis of an ethanolic extract of the plant also revealed the presence of alkaloids, flavonoids, tannins, phenol, cardiac glycosides, anthraquinones. Phytochemical analysis of an ethanolic extract of the plant also revealed the absence of saponins, terpenoids.

\section{Gas Chromatography-Mass spectrometry analysis}

(GC-MS)

Phytochemical components in ethanolic extract of $S$. marianum by GC-MS report. The GC-MS analysis revealed the presence of 10 compounds (Table 2 and 3) from the ethanolic leaves extract of $S$. marianum (Figure 1). From the results, it was observed that presence of $(+)-2$-Born alone, Isobornyl thiocyanoacetate, a-Santoline alcohol, Dodecane, Dodecane, 2,6,11-trimethyl-, Hexadecane, d-Mannose, Undecanoic Acid, 9-Octadecanoic acid, Oleic Acid. Above these compounds were identified based on the RT value, molecular weight, molecular formula, etc (Fig 1) and table 2, 3. 


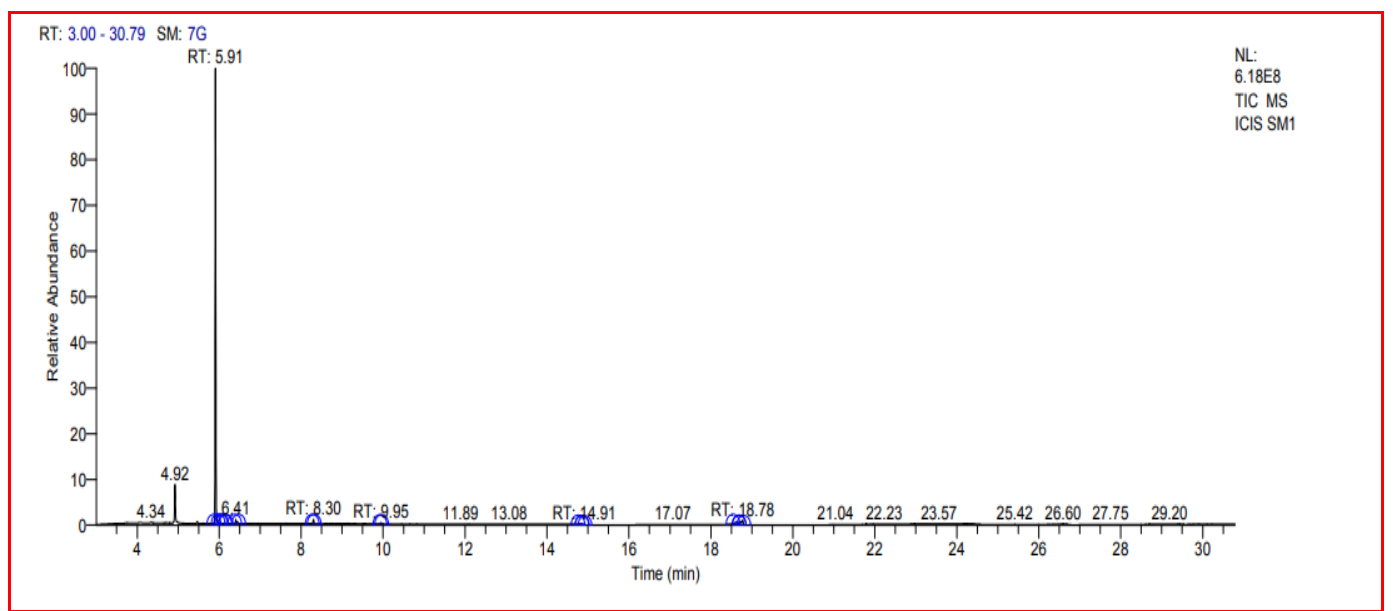

Figure 1: GC-MS CHROMATOGRAM OF Silybum marianum (L).

Table 2: Physical properties of bioactive compounds in S.m (L)

\begin{tabular}{|c|c|c|c|c|}
\hline S.No & $\begin{array}{c}\text { Name of the } \\
\text { Compound }\end{array}$ & RT & $\begin{array}{c}\text { Molecular } \\
\text { Formula }\end{array}$ & $\begin{array}{c}\text { CAS Registry } \\
\text { Number }\end{array}$ \\
\hline 1 & (+)-2-Bornanone & 5.91 & $\mathrm{C}_{10} \mathrm{H}_{16} \mathrm{O}$ & $464-49-3$ \\
\hline 2 & $9,12,15-$ - & 6.05 & $\mathrm{C}_{13} \mathrm{H}_{30} \mathrm{O}$ & $26537-71-3$ \\
\hline 3 & $\alpha-$ Santoline alcohol & 6.15 & $\mathrm{C}_{10} \mathrm{H}_{18} \mathrm{O}$ & $90823-36-2$ \\
\hline 4 & Dodecane & 6.41 & $\mathrm{C}_{12} \mathrm{H}_{26}$ & $112-40-3$ \\
\hline 5 & Dodecane, 2,6,11-trimethyl- & 8.30 & $\mathrm{C}_{15} \mathrm{H}_{32}$ & $31295-56-4$ \\
\hline 6 & Hexadecane & 9.95 & $\mathrm{C}_{16} \mathrm{H}_{34}$ & $544-76-3$ \\
\hline 7 & d-Mannose & 14.79 & $\mathrm{C}_{6} \mathrm{H}_{12} \mathrm{O}_{6}$ & $3458-28-4$ \\
\hline 8 & Undecanoic Acid & 14.91 & $\mathrm{C}_{11} \mathrm{H}_{22} \mathrm{O}_{2}$ & $112-37-8$ \\
\hline 9 & $9-$ Octadecenoic acid & 18.65 & $\mathrm{C}_{18} \mathrm{H}_{32} \mathrm{O}_{2}$ & $26537-70-2$ \\
\hline 10 & Oleic Acid & 18.78 & $\mathrm{C}_{18} \mathrm{H}_{34} \mathrm{O}_{2}$ & $112-80-1$ \\
\hline
\end{tabular}

RT= Retention Time

Table 3: GC-MS Analysis of S.m (L)

\begin{tabular}{|c|c|c|c|c|}
\hline $\begin{array}{l}\text { Name of the } \\
\text { Compound }\end{array}$ & $\begin{array}{l}\text { Nature of the } \\
\text { Compound }\end{array}$ & Structure & $\begin{array}{l}\text { Mol. Wt } \\
\text { (g/mol) }\end{array}$ & Activity \\
\hline$(+)$-2-Bornanone & $\begin{array}{l}\text { Monoterpene } \\
\text { oxide }\end{array}$ & & 152.2334 & $\begin{array}{l}\text { Antitumor, Analgesic } \\
\text { Antibacterial, } \\
\text { Anti-inflammatory } \\
\text { Sedative, Fungicide, } \\
\text { Anticancer. }\end{array}$ \\
\hline $\begin{array}{l}9,12,15- \\
\text { Octadecatrienal }\end{array}$ & Aldehyde & & 262.437 & $\begin{array}{l}\text { Antibacterial and } \\
\text { Antioxidant activity }\end{array}$ \\
\hline$\alpha$-Santoline alcohol & alcohol & & 154.253 & Anticancer effect \\
\hline Dodecane & Alkane & & 170.34 & Antibacterial activity \\
\hline $\begin{array}{l}\text { Dodecane, 2,6,11- } \\
\text { trimethyl- }\end{array}$ & Alkane & & 212.41 & No activity \\
\hline
\end{tabular}




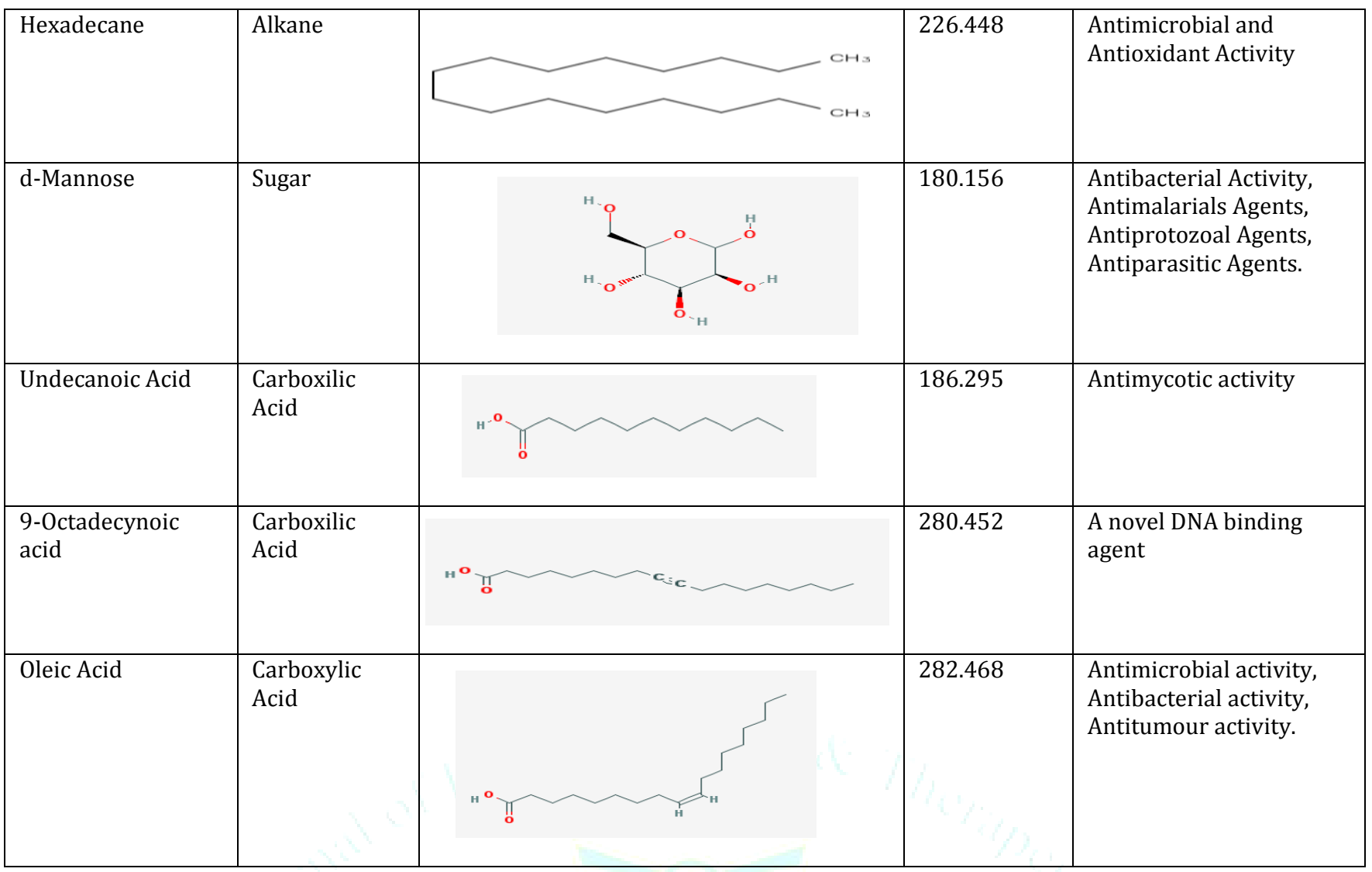

(+)-2-Bornanone is an aromatic compound. It has $5.91 \mathrm{RT}$ value, $\mathrm{C}_{10} \mathrm{H}_{16} \mathrm{O}$ molecular formula and 152.2334 molecular weight. It has anti-tumour, analgesic anti-bacterial, antiinflammatory sedative, fungicide, anticancer activities. It was used as an anti-cancer agent reported by Mariat George et al., (2015) ${ }^{19}$.

9,12,15-Octadecatrienal is an aldehyde compound. It is an aliphatic compound. It has $6.05 \mathrm{RT}$ value, $\mathrm{C}_{13} \mathrm{H}_{30} \mathrm{O}$ molecular formula and 262.437 molecular weight. This compound present in most of the fruit essential oils. This compound has antimicrobial and antioxidant activity 20 .

$\alpha$-Santoline alcohol is an organic and alcohol compound. It has 6.15 RT value, $\mathrm{C}_{10} \mathrm{H}_{18} \mathrm{O}$ molecular formula and 154.253 molecular weight. It has an alcohol-antimicrobial, insecticidal activity 21 .

Dodecane is an aliphatic compound. It has $6.41 \mathrm{RT}$ value, $\mathrm{C}_{12} \mathrm{H}_{26}$ molecular formula and 170.34 molecular weight. Dodecane has antibacterial activity and antifungal activity. It enhances antifungal activity 22 .

Dodecane,2,6,11-trimethyl-, is an aliphatic alkane compound. It has $8.30 \mathrm{RT}$ value, $\mathrm{C}_{15} \mathrm{H}_{32}$ molecular formula and 212.41 molecular weight. It has no activity ${ }^{23}$.

Hexadecane is an aliphatic compound. It has 9.95 RT value, $\mathrm{C}_{16} \mathrm{H}_{34}$ molecular formula and 226.448 molecular weight. It has antimicrobial, antifungal and antioxidant Activity 24,25.

d-Mannose is a C-2 epimer of glucose and occurs naturally in lots of plants and fruits, especially cranberries. It has $14.79 \mathrm{RT}$ value, $\mathrm{C}_{6} \mathrm{H}_{12} \mathrm{O}_{6}$ molecular formula and 180.156 molecular weight. D-mannose plays a role in $\mathrm{T}$ cell activation; we cultured native murine CD4+CD25- T cells in medium supplemented with mannose or other sugars in the presence of $\mathrm{T}$ cell receptor (TCR) stimulation. It is used as an antibacterial activity, antimalarials agents, antiprotozoal agents and antiparasitic agents 26 .

Undecanoic acid (UDA) is a fatty acid have a significant amount of antimycotic activity. It has $14.91 \mathrm{RT}$ value, $\mathrm{C}_{11} \mathrm{H}_{22} \mathrm{O}_{2}$ molecular formula and 186.295 molecular weight. Undecanoic acid (UDA) is one of the most effective fatty acid compounds. It has been suggested that its antimycotic properties are linked to the ability to inhibit the production of exocellular keratinase, lipase and several phospholipids (Das \& Banerjee, 1982) 27.

9-Octadecenoic acid is an aliphatic carboxylic acid. It has 18.65 RT value, $\mathrm{C}_{18} \mathrm{H}_{32} \mathrm{O}$ molecular formula and 280.452 molecular weight. The high concentration of 9-Octadecenoic acid $(8.16 \%)$, in leaf oil, make it potentially useful in the medicines because they exhibit antitumor and antioxidant activities (Dr Duke online database). However, further study has to be conducted for its confirmation. It is worth noting that the methanol extract of $H$. suaveolens L, (Point) has been reported to be used in folk medicine in the treatment of asthma and malaria, cereals conservation and to repel, larvicidal, adulticidal activities of mosquitoes. This compound also has anti-preventive, favour, fungicide, pesticide, perfumery, anti-inflammatory, hypocholesterolemic, cancer preventive effect 28 .

Oleic Acid is an aliphatic carboxylic acid. It has 18.78 RT value, $\mathrm{C}_{18} \mathrm{H}_{34} \mathrm{O}_{2}$ molecular formula and 282.468 molecular weight. It has antimicrobial activity, antibacterial activity and antitumour activity. It has more amount of antibacterial activity 29 .

The plant-based compounds have an effective dosage response and minimum side effects when compared to the synthetic compounds. The studies conducted on Silybum marianum (L) for in vitro biological activities are validated. The presence of most common phytochemicals might be 
responsible for their therapeutic effects. We report the presence of some of the significant components resolved by GC-MS analysis and their biological activities. Thus this type of GC-MS analysis is the first step towards understanding the nature of active principles in this medicinal plant and this type of study will be helpful for further detailed study.

\section{CONCLUSION}

In the present study 10 compounds from the ethanolic leaves extract of Silybum marianum (L). were identified by Gaschromatography- Mass spectrometry (GC-MS) analysis. The biological activities of each of the identified phytocomponents used for antimicrobial, antifungal, antioxidant, anti-tumour and anti-cancer activities. Chemical identification of the plant constituents was conducted based on their retention time (RT), molecular formula, molecular weight and mass spectral data, as well as by computer search mass spectral databases. The chemical structures and medicinal properties also identified. The results revealed the presence of medicinally significant constituents in the plants studied. Therefore, ethanolic extracts from these plants could be seen as a good source for using drugs. The traditional medicine practice is recommended strongly for these plants as well as it is suggested that further work should be carried out to isolate, purify and characterize the active constituents responsible for the biological activity of the organism. Also, additional work is encouraged to see whether these plants have said health benefits, especially as anti-cancer drugs, and elucidate the possible mechanism of action of these extracts. The presence of phytochemicals (secondary metabolites) is responsible for their therapeutic effects. It further reflects hope for the development of many more novel therapeutic agents or templates from such plants which in future may serve for the production of synthetically improved therapeutic agents.

\section{Acknowledgement}

The author is also very grateful to the Secretary and Correspondent and the Principal of A.V.V.M. Sri Pushpam College (Autonomous), Poondi-613 503, Thanjavur (Dt.) for providing the excellent infrastructure and necessary facilities to carry out my research work successfully.

\section{REFERENCES}

1. Bachrach ZY. The contribution of selected medicinal plants for cancer prevention and therapy. Acta Fac Medicae Naissensis 2012; 29(3):117-23.

2. Atanasov AG, Waltenberger B, Pferschy-Wenzig EM, Linder T, Wawrosch C, Uhrin P. Discovery and resupply of pharmacologically active plant-derived natural products: a review. Biotechnol Adv. 2015; 3(8):1582-614.

3. Mohansundari C, Natarajan D, Srinivasan K, Umamaheswari S, Ramachandran A, Antibacterial properties of Passiflora foetida L.- a common exotic medicinal plant, African Journal of Biotechnology. 2007; 6(23):2650-2653.

4. Kirtikar KR, Basu BD. Indian Medicinal Plants. MS Bishen Singh Mahendra Pal Singh D. 1935; 2: 1606-1607.

5. Chopra RN, Nayer SL, Chopra IC. Glossary of Indian Medicinal Plants, CSIR, V ed New Delhi. 1956; 12:157.

6. Rastogi RP, Mehrotra BN. Compendium of Indian Medicinal Plants, Central Drug Research Institute, Lucknow and National Institute of Science Communication, New Delhi, India. 1994; 1-5.

7. De-Fatima A, Modolo LV, Conegero LS, Pilli RA, Ferreira CV, Kohn LK, de- Carvalho JE. Lactones and their derivatives. biological activities, mechanisms of action and potential leads for drug design. Curr Med Chem. 2006; 13:3371-3384.

8. Shahidi F, McDonald J, Chandrasekara A, Zhong Y, Phytochemicals of foods, beverages and fruit vinegar: chemistry and health effects, Asia Pacific J Clin Nutr. 2008; 17:380-382.
9. Vasu K, Goud J, Suryam V, Singara A, Chary M. Biomolecular and phytochemical analyses of three aquatic angiosperms. African Journal of Microbiology Research, 2009; 3(8):418-21.

10. Prasain JK, Wang CC, Barnes S. Mass spectroscopic methods for the determination of flavonoids in biological samples. Free Radical Biology \& Medicine. 2004; 37:1324-50.

11. Rajendra Yonzone, Lama D, Bhujel RB, Samuel Rai. Orchid species diversity of Darjeeling Himalaya of India. Int. J. of Pharm. \& Life Scie. 2012; 3(3): 1533-1550.

12. Robertson DG. Metabonomics in toxicology: A review. Toxicol. Sci. 2005; 85:809-22.

13. Fernie AR, Trethewey RN, Krotzky AJ, Willmitzer L. Metabolite profiling: From diagnostics to systems biology. Nat Rev Mol Cell Biol. 2004; 5:763-9.

14. Kell DB, Brown M, Davey HM, Dunn WB, Spasic I, Oliver SG. Metabolic footprinting and systems biology: The medium is the message. Nat Rev Microbiol 2005; 3:557-65.

15. Corchete P. Silybum marianum (L.) Gaertn: the Source of Silymarin. In: Bioactive Molecules and Medicinal Plants, Ramawat KG, Mérillon JM (eds.). 2008; 123-148.

16. Ladas EJ, Cheng B, Hughes D. Milk thistle (Silybum marianum) is associated with reductions in liver function tests (LFTs) in children undergoing therapy for acute lymphoblastic leukaemia (ALL). Society of Integrative Oncology, Boston, Mass. 2006; 5(7):1000292.

17. Bhatia N, Zhao J, Wolf DM. Inhibition of human carcinoma cell growth and DNA synthesis by silibinin, an active constituent of milk thistle: comparison with silymarin. Cancer Lett. 1999; 147:77-84.

18. Harborne JB. Phytochemical Methods. London: Chapman and Hall Ltd. 1973; 49-188.

19. Mariat George. Phytochemical and Antioxidant studies on the essential oil of the rhizome of Curcuma aeruginosa (Roxb). International Research Journal of Pharmacy. 2015; 6(8):573579.

20. Ardalan Pasdaran, Arsalan Pasdaran, Nazim Mamedov. Antibacterial and Antioxidant Activities of the Volatile Composition of the Flower and Fruit of Solanum sisymbrifolium (Litchi Tomato). Pharmaceutical Sciences. 2017; 23:66-71.

21. Srinivasan K, Kumaravel S. Unraveling the potential phytochemical compounds of Gymnema Sylvestre through GCms study. Int J Pharm Pharm Sci. 2015; 8(1):450-453.

22. Cheila DOS, Fabricio MC, Fabricio AO, Evandro P, Carmen BBF, Susana MWS, Maria, LS. Antimicrobial activity [2methacryloyloxy) ethyl] trimethyl ammonium chloride against Candida spp. 2012; 1-4.

23. Ramalingam Vidhya and Rajangam Udayakumar. Gas Chromatography-Mass Spectrometry (GC-MS) Analysis of Ethanolic Extracts of Aerva lanata (L.). International Journal of Biochemistry Research \& Review. 2015;7(4):192-203.

24. Yogeswari S, Ramalakshmi SN, Muthu JM. Identification and comparative studies of different volatile fractions from Monochaetia kansensis by GC-MS. Global Journal of Pharmacology. 2012; 6(2):65-71.

25. Hsouna AB, Trixie M, Mansour RB, Jarraya RM, Damak M, Jaoua S. Chemical composition, cytotoxicity effect and antimicrobial activity of Ceratonia siliqua essential oil with preservative effects against listeria inoculated in minced beef meat. International Journal of Food Microbiology. 2011; 148(1):66-72.

26. Davis, J.A. \& Freeze, H.H. Studies of mannose metabolism and effects of long-term Mannose ingestion in the mouse. Biochimica et Biophysica Acta. 2001; 1528:116-126.

27. Das SK, Banerjee AB. Effect of undecanoic acid on the production of exocellular lipolytic and keratinolytic enzymes by undecanoic acid-sensitive and -resistant strains of Trichophyton rubrum. Sabouraudia. 1982; 20:179-184.

28. Mohamed Ismail A, Sheik Jahabar Ali H. Phytochemical diversity on the leaves of methanol extract of Hyptis suaveolens L (point.) From Cuddalore (Chidambaram) district, Tamil Nadu, India. International Journal of Recent Scientific Research. 2017; 8(12):22863-22866

29. Awa EP, Ibrahim S, Ameh DA. GC/MS analysis and antimicrobial activity of diethyl ether fraction of methanolic extract from the stem bark of Annona senegalensis Pers. Int. J. Pharm. Sci. Res. 2012; 3:4213-4218. 